\title{
The 1995 Report on the IPCC (Intergovernmental Panel on Climate Change) Working Group II - Chapter 17 - Financial Services
}

\author{
by Andrew F. Dlugolecki*
}

\section{The 1990 IPCC Report}

Economic activity, farming and leisure all create waste gases which have altered the composition of the Earth's atmosphere significantly over the last century. The temperature of the atmosphere has risen by over one half of a degree in the same period. Scientists and politicans have become concerned about the impact of this on society and the natural world. Potentially, the additional gases will create a "Greenhouse Effect", leading to changes in weather patterns, higher sea levels, and warmer temperatures (Global Warming). Judging the urgency of the problem is difficult because of the various hidden influences. Scientists clearly have an interest in possessing a complex, but not-quite- solved problem which requires more research funds. They are also reluctant to give "probability" assessments. The environmental lobby clearly thrives of a big threat and, in fact, some groups over-exploited the 1990 IPCC report, leading to the danger of crying wolf once too often. Several large industrial associations have taken an aggressive stand against climate change emphasizing that uncertainty is great, the cost of changing technology is high and that some areas may even benefit, eg temperate latitudes may have a longer growing season.

The first major scientific report on this was published in 1990 by a UN agency, the Intergovernmental Panel on Climate Change (IPCC). The work was confined to reviewing existing literature; new research was not commissioned. Working Group I considered the scientific basis of climate change. Working Group II looked at the impact on the natural world and society while Working Group III explored the options available to policymakers.

The report confirmed that there was a problem, although there was considerable uncertainty about the magnitude and rate of change. By the year 2025 it was expected that manmade gases would have reached double the natural level of carbon dioxide. If this position then stabilized it will likely result in an increase in temperature of between 1.5 and 4.5 degrees centigrade. Sea levels would rise by about 65 centimetres with a wide margin of error. It would take many years for these changes to occur due to inertia in the natural climate system, particularly the oceans. On the other hand, it is virtually certain that the situation would not stabilise in 2025 but would, in fact, continue to progress thereafter, leading

\footnotetext{
* Group Assistant General Manager - Underwriting, General Accident Fire and Life Assurance Corporation, Perth, Scotland.
} 
to accelerating changes in temperature and sea level with unknown impacts on weather patterns. Working Group II considered the impact on the natural world and society and concluded that the major impacts would be on natural ecosystems and the availability of water. Because agriculture is very closely related to the natural world it too would be seriously affected in certain countries. Furthermore, coastal zones and less developed countries without the financial resources to cope with change would also suffer.

Working Group III looking at the policy options made several points. It recommended that emissions should be limited to try to put a brake on the whole process, that policymakers should begin to plan for change through techniques such as coastal zone management, and that a programme of research and education was necessary to raise overall awareness of the problem. Finally, they made the point that as less developed countries lacked the resources to cope with major problems, there would be a necessity for funds and technology to be transferred from the developed world to the poorest nations.

\section{Recent experience in property insurance}

The insurance industry is currently under stress from a series of "Billion Dollar" storms since 1987, resulting in dramatic increases in claims, reduced availability of insurance, and higher premiums. These higher losses reflect significant increases in infrastructure and economic worth, as well as a possible shift in the intensity and frequency of extreme weather events. The position has been exacerbated by a general movement of population in certain countries like the United States towards more vulnerable areas such as the coasts of Florida.

\section{"Billion Dollar" storms}

\begin{tabular}{clc} 
Year & \multicolumn{1}{c}{ Event } & $\begin{array}{c}\text { Insured } \\
\text { Cost (\$B) }\end{array}$ \\
\hline 1987 & "Hurricane" in SE England / NW France & $\$ 2.5$ \\
1988 & Hurricane Gilbert in Jamaica / Mexico & $\$ 0.8$ \\
1989 & Hurricane Hugo in Puerto Rico / S. Caroline & $\$ 5.8$ \\
1990 & 4 European Storms & $\$ 10.4$ \\
1991 & Typhoon Mireille in Japan & $\$ 4.8$ \\
1992 & Hurricane Andrew in Florida & $\$ 16.5$ \\
1993 & "Storm of the Century" in Eastern USA & $\$ 1.7$ \\
1995 & Hailstorms in Texas & $\$ 1.1$ \\
1995 & Hurricane Opal in Southern USA & $\$ 2.1$
\end{tabular}

(Parallel trends in drought and flood losses have often not been insured, placing the burden directly on other sectors). Although the figures for losses are alarming, computer simulations indicate that already a $\$ 50$ billion insured loss is possible in the United States from a single hurricane. This would probably be critical for the insurance industry in that country. Indeed Hurricane Andrew made several smaller insurers bankrupt and created severe difficulties for the Florida insurance market. The report considers as a case study the effect of Hurricane Gilbert in Jamaica in 1988, which illustrates the difficulty for small countries of coping with such events even when significant reinsurance is available, as it was at the time. 
It is a moot point whether the trends in storm costs do indeed reveal a change in weather patterns. Most meteorologists are reluctant to conclude that there has been a significant change in weather patterns because of the natural variability inherent in the climate system and the sparseness of good meteorological records. However, research done by this author does indicate a significant change in the weather in North West Europe over the last $40 / 50$ years. Such changes have in the past been related to major storms. It does also seem that the experience on household buildings in the UK which is a fairly static sector, has deteriorated significantly over the last 30 years due to changing weather in the UK. A side effect which the report also mentioned was the need for financial services operations to be able to cope with the disruption caused to daily activities by severe weather such as denial of access and failure of power supply.

Traditionally the insurance industry has adopted four strategies to cope with changes in risk. These are limiting the risk, physical risk management, transferring the risk and technical pricing. The report discussed these in some detail and then went on to consider further options which might be available in a situation of fundamental change. Limiting the risk through measures such as selective underwriting or the use of deductibles and co-insurance can help to significantly reduce the bottom line impact of extreme weather events to the insurer. However, such measures may cause problems for the other sectors of the economy through the restricted availability of the insurance product itself. In many countries governments have intervened in the market to ensure that wide coverage is available. The option of physical risk management is an attractive one but it does require a considerable effort to be effective. Insurance companies have taken many steps to ensure a better control of damage after it has occurred, through the availability of 24 hour telephone helplines and competition. Insurers will, of course, still require reinsurance to cope with super-catastrophes or multiple hits.

Instead of dealing with problems piecemeal the insurance industry needs to influence the decisions of a wide variety of bodies and policymakers at the strategic level. Firstly, the construction industry regarding the methods and standards and regulation of construction. Secondly, government and its various departments to resist new development in high risk areas, to protect existing developments in high risk areas, and to plan how insurance can help society cope with extreme events. The insurance sector can help the authorities improve the response to property damage from such events through providing information on the cost of weather hazards, advice on vulnerable construction design and disaster recovery services. However, the insurance industry is not likely to be able to provide all the necessary funds for the post-disaster reconstruction.

Finally, there needs to be some form of international body to reflect the concerns of insurers. Many issues now are trans-national such as pollution, competition, communication and climate change. The insurance industry has no international underwriting organisation and this now seems an important gap. Indeed this has helped to bring about the formation of the United Nations Environment Programme (UNEP) Initiative for the Insurance Industry on Sustainable Development and the Environment. This will give the insurance industry its own international voice on climate change and other important environmental issues. We think that we can help policymakers to discover appropriate solutions to cope with the financial challenges. Our practical skills can be strengthened through research, and applied through co-operation with other stakeholders. Furthermore, a well-directed programme of communication can improve society's response and raise the general level of practice within the insurance industry. 


\section{Non-property insurance}

Outside property insurance there is little literature on the issue of climate or weather. There is no major study on the effect on insurers of extreme conditions in the transport sector, for example, although motor insurance and transport insurance in general is a very important field for insurers. Similarly, in liability insurance the emphasis has been rather on environmental pollution claims rather than in looking at the impacts of the weather where it is often difficult to prove negligence or to identify a currently pursuable person or organisation. There has been some litigation in this field, for example, the control of tree root invasion into neighbouring buildings, control of undergrowth following bush fires in Australia, limitation of beach erosion and even the accuracy of weather forecasts and flood control. However, at present this is not a major area nor does it seem to be in the future. Agriculture is a key sector in many nations, though often not part of the market economy. In most countries insurers do not offer coverage for growing crops because of the possibility of catastrophic loss and the difficulties of loss control and evaluation. The situation is also complicated by the relatively liberal granting of disaster relief by government in times of hardship which discourages the prudent farmer from buying insurance at all. Climate change is expected to have significant impacts on agriculture so it may be expected that interest in this area will increase.

In principle, life and health underwriting could also be affected through changes in human mortality such changes are associated particularly with extremes of heat and cold. However, such changes are difficult to predict and there are so many other factors, for example, disease involved that at present the life and pensions industry is taking little interest in this factor.

With education all parties in the property market must be made fully aware of the potential effects of climate change and informed of the means available to combat these impacts. Disaster plans must be prepared at all levels. These should incorporate property owners and occupiers, architects and builders, insurers and regulatory authorities.

Next we come to integrated financial mechanisms. If the probability of an event is very low consumers act as if it will never happen, even if the probable maximum loss is very high. With better information it will be possible to assess the risk exposure of individual entities and the nation as a whole. This will serve as a basis for discussion about which risks can be borne by the private sector. Where is risk is too hazardous for private insurance companies there are still many advantages in involving the private insurance sector in planning for disaster mitigation. Their practical knowledge of marketing a financial product, tariff structures, access to international resources, damage recovery, avoidance of duplicate administration and fraud control would prove invaluable.

The availability and affordability of climate data for research and commercial decisionmaking is critical but this resource is increasingly seen by governments as a commercial opportunity rather than one for the public good.

Within the construction industry the authorities must work with trade associations to improve building quality and design and also consider how to retrofit structures as necessary. Finally, in view of the long-term nature of much financial activity particularly pension funding, it would be valuable for governments to give an early indication of how they might modify policy on industries that contribute to or counter global warming and then act consistently so that investment can be channelled efficiently. Initially subsidies may be important for research and development in novel technologies. 


\section{The way ahead}

So let us now consider the next steps for the financial sector. Firstly, we need to know what future weather patterns will be like. We need to know what will change, where, when and how much. This is really a task for government funding but the financial sector should monitor new findings constantly.

Secondly, we need to identify the key hazards, the ones which will be very costly, and then work with other stake-holders to ensure that those hazards are minimised as much as possible. The issue of coastal flooding is one which I think is particularly urgent. The sector can co-operate with governments and the professions to reduce critical risks, try to ensure the availability of essential cover and also build-up reserves to cope with the uneven incidence of large losses. It is important to look for "no regret" options, ie. actions which incur little or no additional cost but may reduce the potential impact of climate change. Thus it is probably not sensible to develop land vulnerable to coastal inundation. On the other hand, investigating solar, wind or wave power may be a good long-term option.

The whole question of educating stake-holders is a key one. There is still a remarkable degree of ignorance in the financial sector about the potential impact of climate change. It is critical that decision-makers on all levels understand the issue that they can achieve satisfactory corporate performance in the short and long-term. Trade and professional bodies are beginning to tackle this but many countries are well behind and there is a natural conservatism in the financial sector, particularly when scientists are cautious about making detailed statements on future developments.

Is it appropriate for the insurance industry or the financial sector in general to lobby on emission controls? This is a controversial question. Many think it is premature to become engaged in this activity. I believe it is very valuable to place before the policymakers the current vulnerability of society to extreme events, so that they are aware of the economic implications, and can begin to appreciate the potential for even greater losses if the dice rolls badly. 